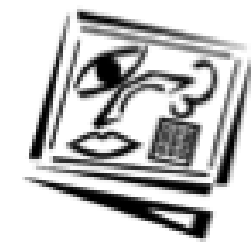

\title{
Multimedia, magic and the way students respond to a situated learning environment
}

\author{
Jan Herrington and Ron Oliver \\ Edith Cowan University
}

\section{Interactive multimedia and situated learning}

Interactive multimedia is a relatively new educational innovation in primary, secondary and tertiary level classrooms. While the educational community has enthusiastically embraced its potential, relatively little is known about how students learn from multimedia, and the design features of the software itself that promote effective learning. This article describes results associated with a qualitative study into how students use an interactive multimedia program designed according to a situated learning model.

Situated learning first came to prominence with the publication of several articles in the late 1980s (e.g., Brown, Collins, \& Duguid, 1989; Collins, Brown, \& Newman, 1989). The theory captured educators' imagination with its foundations in the apprenticeship system, and its emphasis on the importance of learning within the context of real-world applications. The practical application of the theory to the design of interactive multimedia was made possible by the definition of nine critical characteristics of a situated learning model (Herrington \& Oliver, 1995) from the extensive literature on the subject. The learning environment used in the study needed to:

- Provide an authentic context that reflects the way the knowledge will be used in real-life

- Provide authentic activities

- Provide access to expert performances and the modelling of processes

- Provide multiple roles and perspectives

- Support collaborative construction of knowledge

- Promote reflection to enable abstractions to be formed 
- Promote articulation to enable tacit knowledge to be made explicit

- Provide coaching and scaffolding at critical times

- Provide for integrated assessment of learning within the tasks.

Each of these characteristics was operationalised within the design of an interactive multimedia learning environment entitled Investigating assessment strategies in mathematics classrooms (Herrington, Sparrow, Herrington, \& Oliver, 1997). Many aspects of the model could not be incorporated into software per se, such as opportunities for reflection or articulation. However, it was important to ensure that the software did not prevent these aspects occurring by restrictive design. The critical guidelines for the design of the multimedia software, to enable it to support a situated learning environment, were that the program needed to provide:

- a physical environment reflecting the way the knowledge will ultimately be used (Brown, et al., 1989; Collins, 1988; Young \& McNeese, 1993)

- a non-linear design to preserve the complexity of the real-life setting (Brown, et al., 1989; Collins, 1988; Young \& McNeese, 1993)

- a large number of resources to enable sustained examination from a number of different perspectives (Spiro, Vispoel, Schmitz, Samarapungavan, \& Boeger, 1987; Young \& McNeese, 1993; Brown, et al., 1989; Collins, 1988).

All of these principles were manifested in the interactive multimedia program in the design of the interface, the presentation of the media elements and in the means of navigation. The program interface simulates the front part of a classroom where students can click on the elements to access a variety of resources on 22 different assessment strategies appropriate for K-12 mathematics (Figure 1).

The assessment program is designed for novice users of computers: computer experience is not a prerequisite for use. Those using the program are given a choice of five complex and authentic investigations to complete which require sustained examination of the resource, and the production of both a written report and a verbal presentation. For example, in one investigation, students are given two memos: one from a parent requesting that her anxious child be assessed in ways other than pencil-and-paper tests; and the other from the Mathematics Coordinator requesting a new plan for the assessment of mathematics in the school based on recent research and best practice. The program is designed so that students use the 
multimedia resources to research and prepare their plan, which they can then present as a report at the next 'staff meeting' as well as a written proposal to the Principal of the school.

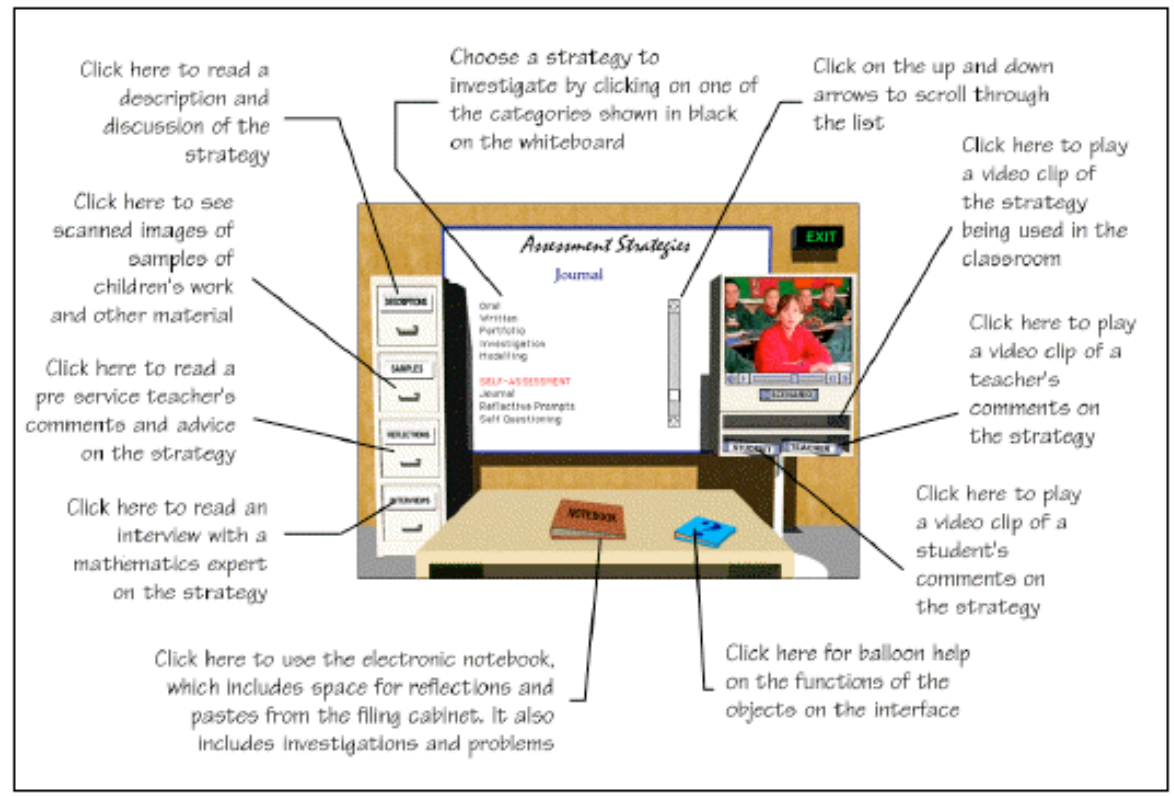

Figure 1: The main interface of the assessment program

\section{The research study}

The purpose of this study was to investigate patterns of behaviour of students immersed in a multimedia situated learning environment using this resource. Eight preservice teachers in the second year of their undergraduate university course (four groups of two) were videotaped using the program over two semester weeks as they completed the authentic task. In the third week, the students gave their presentations to the class, and shortly after, were interviewed. None of the students in the study had significant previous exposure to computers or multimedia programs and this did not appear to impede their effective use of the program.

Techniques of qualitative analysis recommended by Miles and Huberman (1994), Eisner (1991) and McCracken (1988) were used to analyse the data collected from the interviews, the transcripts of observation of their program use, and other documentary evidence and notes. The analysis involved the three step process proposed by Miles and Huberman: data 
reduction, data display, and conclusion drawing and verification. The analysis was done with the assistance of NUDIST (Qualitative Solutions \& Research, 1993), a computer-based qualitative analysis program.

\section{Outcomes and findings}

Any study of learning is well informed by descriptions of the activity and behaviour of the learners since this has the capacity to significantly influence what is learned and how it might be applied later. From a 'crosscase' analysis of the transcripts of the interviews and students' talk as they used the interactive multimedia program, themes and trends emerged which began to illuminate the subject of how students used the interactive multimedia program which incorporated the characteristics of a situated learning environment. Each of these themes-Technology as magic, Interface, Navigation, and Search strategies - is discussed in detail below.

\section{Technology as magic}

Arthur C. Clarke (1973) in his book Profiles of the future: An inquiry into the limits of the possible, described advanced technology as 'indistinguishable from magic' (p. 39). Others have repeated this theme in relation to interactive multimedia where many refer to its 'magical qualities' (e.g., Morrison, 1994). For example, John Sculley, Chief Executive of Apple Computer, Inc., in 1988 described the potential of multimedia learning environments:

Teachers and students will command a rich learning environment that, had you described it to me when I was at school, would have seemed entirely magical ... Imagine a screen that can display in vivid colour the inner workings of a cell, the births and deaths of stars, the clashes of armies, and the triumphs of art. And then imagine that you have access to all of this and more by exerting little more effort than simply asking for it to appear. It seems like magic, even today. (Sculley, 1988, p. vii)

The active nature of learning, the multitude of choice and the ease of access attributed to interactive multimedia by Sculley, are all mirrored in the following comment from one of the students:

Oh I liked it, it was much more interesting than sitting in a classroom listening to a lecturer because you choose your own information that you want to know, and you're actually doing it. And it is easy, like you don't have to look around the library for everything that you want. It was all there for you. (Interview with Louise) 
The sense of magic and amazement at what the students were able to do was also evident. They had not been sufficiently exposed to multimedia to lose that sense of wonder and excitement that is to be found in the use of a new technology. For example, one student expressed wonderment at the capabilities of computers:

It's just so amazing what computers can do, and how things are done.

(Interview with Debra)

Another student referred to the program as something children would have fun with, expressing his own childlike sense of fun:

It was something different to start off with, not just the boring handout or something ... it made a lot of sense and it was good to play around. Sort of things ... kids would have fun with. (Interview with Rowan)

The spontaneous amazement and delight of one student was obvious when he realised the scope and extent of the multimedia resource as he used the program:

Mega! So this is a massive, massive database. (Observation of Carlo using multimedia program)

In discussing the positive aspects of the assessment program, students frequently mentioned its motivational ability. Generally, they attributed the motivational power of the learning environment to four aspects. Firstly, many students felt that the fact that they could work at their own pace was motivating. They made frequent references to the alternative scenario, such as, 'not just the same old boring thing', comparing the more restricted lecture-based approach to the freedom the assessment program allowed. Secondly, several students mentioned the motivating influence of the partner working in the small collaborative groups. For example, one student mentioned that his partner kept him motivated by keeping him on task. A third motivating influence mentioned by one student was the authentic assessment of the task, both for its intrinsic interest and the fact that it was being graded. Fourthly, many students mentioned the inherent motivation of computer-based learning, although this was qualified in many instances. For example, one student hinted that the motivating power of a computer was in its novelty:

I don't think you can learn everything on a computer, so I think that was why it was most motivating cause we'd never done it before. (Interview with Zoe) 
Other students were more wholehearted in their endorsement of computerbased learning, for example, the following comment was typical of these positive comments:

I find anything on the computer quite motivating. (Interview with Evie)

The students frequently mentioned the word fun in their descriptions of the use of the assessment program, not as they were using the programs, but in their reflective responses to the interview questions. One might suspect, however that the fun might more usefully described, as it was by a young student working on a LEGO/Logo problem, as 'hard fun' (Negroponte, 1995, p. 196). The students made comments such as the following:

It was fun, it was something different. (Interview with Rowan)

It was a different approach, it was fun. (Interview with Evie)

It is fun, it's more fun, it gets you a bit more into it. (Interview with Carlo)

It was set up in a fun way. (Interview with Debra)

However, this positive response to the motivating magic of the interactive multimedia experienced by the students was countered by feelings of annoyance in dealing with technical problems, described by Clifford Stoll as 'the computer's universal ability to generate frustration' (Stoll, 1995, p. 60). Stoll and others (e.g. Cuban, 1996; Postman, 1992; Spillane, 1997; Slattery, 1995) have been vocal in pointing out the shortcomings of computers in learning environments. They argue that, despite the sometimes exaggerated claims made for the potential of computers, traditional methods such as print, pencils, paper and the post, are often faster, more efficient and more economical than the computer-based alternatives. None of the technical problems experienced by the students was severe enough to impede their effective use of the resource, but they clearly caused annoyance and frustration, and distracted them from the task. Some of these annoyances related to the program itself:

If we were watching the video and we found something important, and we clicked into the notebook, and then the video wasn't in any more. Like we would pause so we still wanted it to be same position but we'd have to start it all again. Yes, so that was a bit annoying. (Interview with Zoe)

Some problems were possibly caused by a computer in the laboratory not meeting the minimum requirements specified to run the software. For example, some of the video clips were very jerky or did not run while the soundtrack continued to play: 
And the video, you'd hear the voice over but it looked like the video was dragging, like not connecting. And on some of them we couldn't even hear the audio. It kept on cutting out. Just little things like that, that was the only thing that really made it a bit harder for us. (Interview with Louise)

Other frustrations were caused by the sheer unpredictability of computer technology, the myriad of unexplained happenings which conspire to defeat the human users, such as system crashes, disappearing desktop icons and disks refusing to eject. Apart from the expletives occasionally detected on the recordings as students used the program, this kind of frustration was summed up by a student in the following comment:

Ours had a few glitches and that was really annoying. And just basically computer problems, like our mouse wouldn't work, and the disk wouldn't save. (Interview with Louise)

In dealing with computer technology, students experienced both the motivating, magical wonderment that advanced technology can provide, as well as the inevitable frustrations that plague every computer user. It is possible that with future use, both will move from the extremities of the continuum: with regular use, students will take for granted the capabilities of the technology and no longer marvel at the magical qualities of multimedia; and computer technology will improve to the point where technical problems no longer generate barely-containable frustration.

\section{Interface}

The user interface of the interactive multimedia program on assessment was designed to reflect the real life context of a classroom. An ecological or intuitive interface design (i.e., objects within a context) was favoured over a lexical design (i.e., words on buttons) as it was more in keeping with the situated learning characteristics upon which the program was modelled. Such an interface can quickly become intuitive in its use as there is no need for the processing of the labels on buttons to intervene in the action of retrieving the information (Hedberg \& Harper, 1996; Pejtersen, 1993). Negroponte (1995), in his discussion of the 'secret to interface design' writes:

When you meet somebody for the first time, you may be very conscious of their looks, speech and gestures. But quickly, the content of your communication dominates, even if it is largely expressed through tone of voice or the language of facial expressions. A good computer interface should behave similarly. (pp.93-94) 
Students responded positively to the interface. They appreciated the classroom context, and there was no hint that they felt patronised by pictures rather than words. The following comment indicates that this student was very aware of the difference between the ecological interface employed by the assessment program, and the alternative lexical design:

It was set up in a fun way, like it was a classroom. You had your video sitting there, you didn't just have the word 'video' and it didn't have the word 'filing cabinet' there. It was all there with pictures and you could relate it all. (Interview with Debra)

Another described a similar button-based interface design in the following comment, suggesting that he had been exposed to this design before, and interestingly, equated it with the traditional method of university teaching from the blackboard:

The last thing you want is ... a screen you scroll down, then it gives you the heading of whatever subject it is and a description, and maybe it could have a 'Press play' for the videos. It's just looking at a boring computer screen. You could do that straight off the [black]board. What's the difference? (Interview with Rowan)

Sound effects were used in the program to provide instant feedback to students that the choice they had selected had been effected. For example, clicking on a filing cabinet drawer gave a squeak as the drawer opened before the document 'in the drawer' appeared on the full screen. Students responded favourably to this feature as well:

One thing I will always remember. I went to open the filing cabinet and it squeaked. That was excellent ... the first time I heard it, you know, I nearly laughed my head off. (Interview with Rowan)

Students generally found the interface was logical in its layout and very easy to use. The students appeared to conceptualise the layout of the various resources and their contents very quickly. One student mentioned that you always knew where to find things. Another compared the simplicity of the ecological interface favourably with the verbal nature of the Internet, and that he could just click on what he wanted without having to search.

The one feature almost all the students disliked about the program was the size of the video picture. All the video clips appeared in the area given to the television screen, a space with dimensions of approximately $5 \mathrm{~cm}$ by $4 \mathrm{~cm}$. The size was limited by technical constraints and the limited memory capacity of CD-ROMs, an important consideration when dealing with 
memory-intensive files such as Quicktime video files. Some students mentioned that they would have preferred the picture to be much bigger. Norman (1993) points out that larger screen size enables viewers to be 'captured by the event' and 'sensory experience is maximized' (p. 34).

One interesting trend which emerged from the interviews (and this is reflected in the quite considerable literature on 'designers as learners', cf. Jonassen \& Reeves, 1996) was the students' enthusiasm for suggesting what could have been done with the interface. One student, made the point that the size of the video screen, while suitable for tertiary students, would have to be made bigger for younger children. In so doing he was not discussing how he found the program's interface, but had moved into general interface design considerations from the perspective of a potential user group. Another student suggested that there should have been an apple sitting on the desk. When questioned what the apple might do if it was clicked, the student became quite excited about the possibilities:

Say 'Take a lunch break'. Or when they'd had enough [time working on the program], you could have a worm come out. (Interview with Zoe)

Similarly, David felt that the notebook should have been instantly accessible at all times, and proposed an interface design which would have allowed it:

I actually do think a good idea would have been to split the screen to have the notebook one side, and what you are reading or watching on the other. So you could just like cut and paste. (Interview with David)

Generally, students adapted very quickly to the layout of the interface, and found the resources easy to access and use.

\section{Navigation}

The organisation of information and material in multimedia programs can vary significantly. At one end of the continuum, material is presented sequentially, in a linear fashion, where students' choice of movement is limited to going forward or backward. At the other end of the continuum, students have unlimited choice in accessing material (see Figure 2).

Navigation systems are provided in interactive multimedia programs to enable the user to move around and investigate the resource. The purpose of navigation tools within a multimedia program is to: locate and access particular information or instructional nodes, purposefully move between 
related information or instructional nodes, to establish one's current position within the information or instructional base, and to return to known reference points (Oliver \& Herrington, 1995).
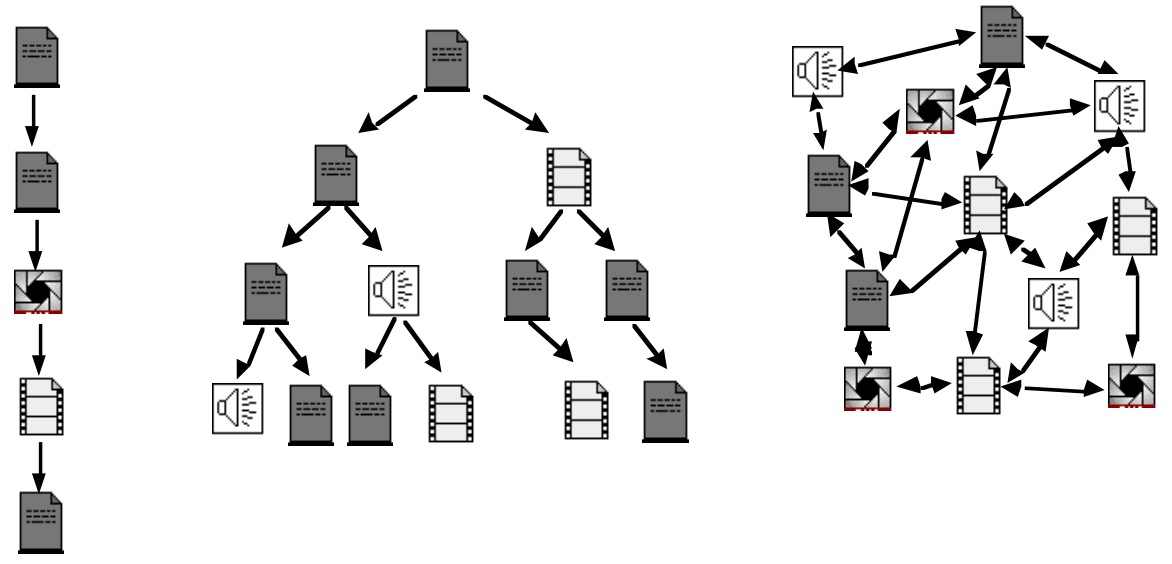

sequential

linear branching

referential linking

Figure 2: Continuum of multimedia organisation (Oliver \& Herrington, 1995)

The program used in the study was designed to provide referential linking to enable students to readily access any media element or document, together with the notebook and the help screen. All elements are accessible from the main interface, and all clickable objects lead only to a single branch, that is, no submenus appear when objects are clicked. Generally, students had very little trouble acquainting themselves with the navigational systems provided by the program, and they readily accomplished the means to investigate the resources. A typical comment was one such as this:

It was just so simple to use because it's all there ... there's a clear way to get back to it. You don't feel like you're getting lost. (Interview with Debra)

The students appreciated the non-linear layout of the program from a navigational perspective. The freedom to access material in the order of their own choosing was commented on by a number of students. For example, this student noted that the program did not force the user to complete elements of the program in sequence: 
You could go through and do whatever you like. It doesn't say you have to do this bit first, and then that bit. You could go and do whatever. (Interview with Debra)

One student compared the navigation of the assessment program to a more linear structure he had experienced in another computer-based program:

You can't get lost in it like some programs, you know if you go into this and you go into that, then to that. When you want to go back out it is a bit rough ... To go back you have to like go back eighteen pages, and you have to go back another five, forward another eighteen pages. (Interview with Carlo)

Some students also commented on the fact that the notebook could be accessed from any point in the program and that this complemented the non-linear nature of the package. The following comment by a student implies that the ease of access of the notebook facilitated his ability to reflect as he used the program:

I liked being able to do things at my speed, and I like the notebook, being able to flip to the notebook from anywhere, and being able to jot down what you're thinking. (Interview with Glen)

Knowing where to look without the fear of getting lost was obviously an important consideration in the students' use of the program, and the relatively straightforward nature of the program was compared to information-seeking on the Internet. The comment by this student indicates frustration with searching in a labyrinth:

It was very well set out and you didn't have to go looking for things like when you're 'netting', you have to go, 'Well it might be in here, or here', and you look in there, so it leads to something else and you have to go back where you started. (Interview with Glen)

Methods of tracking progress in hypermedia environments have been likened to the mythical Theseus who laid a thread to retrace his journey through the maze of passages in the Labyrinth of Daedalus (Harnden \& Stringer, 1993; Stringer, 1992). The students' comments on the navigational ease of the assessment program indicates that no retracing aid is needed. The navigational systems in the program provide students with a relatively flexible, referential system where any node of information is accessible within two clicks of the mouse. One student described the simplicity of the navigation process:

It's just the fact that you can reflect as well, you can go back. And once you have seen one video you think 'What did they say in that one back there?'

Click, back up to the top and have a look. And it's all quick as well. Like 
it's not a long process where you've forgotten what you're after. It's still in your head. You're thinking 'Oh yes, oh yes, fair enough' and it's upwards and back. You can do it and go back and then go back to your notebook and make notes. (Interview with Carlo)

The means of navigation used by the students as they worked with the interactive multimedia program on assessment was generally found to be comparatively simple and effortless. Students had little difficulty finding what they were looking for, and were quickly able to return to the main interface without having to follow links through several layers of materials with the possibility of not finding their way back.

\section{Search strategies}

In order to complete the task, students used navigation strategies to access the various media elements and to search through the materials in a purposeful manner. An audit trail (Schwier \& Misanchuk, 1993) was made from data provided on the videotapes to determine the manner in which the groups accessed the material.

Search strategies employed by students varied considerably between groups. Students could choose to approach the search systematically, or use an unstructured path through the program. All the groups approached the task systematically opting either to investigate the resource by strategy (the assessment strategies written on the whiteboard in the interface) or by media element (the video clips or the documents in the filing cabinet).

Interestingly, each group used a different search path to examine the materials and purposefully seek information. Three initial steps, however, were common to all groups at the beginning of their use of the program. Firstly, they used an initial orientation strategy where the students moved almost randomly around the resource, clicking here and there, trying out elements and determining the scope of the resource. The following statement summarises the approach:

Firstly we went through, just picked out things of interest to see what the package was about, just to see what it had to offer. We did that with about five different ones, made a few notes on it ... But we spent the first five minutes on interest, just seeing what it was like, playing around with it to see what it could do. (Interview with Rowan)

Secondly, every group of students returned to examine the task they had been set, either in the electronic form in the notebook, or the hard copy form which they had received as a handout. Students took a few minutes to 
reassess the task in the light of the scope of the resource; and then thirdly, each group planned an initial strategy, or first move on how they might proceed to begin. For example, Steps 2 and 3 are illustrated in the following excerpt:

Debra: So are we going to do one from each category? Is that how you want to do it?

Glen: Not necessarily. Let's just read the question again. (Look at activity for 4 minutes).

Debra: What does it want us to do?

Glen: So we have to decide which ones we're going to use and then look at the advantages. It actually just says 'formally request that you prepare a report on alternative approaches to assessment in mathematics to be presented to staff. Right it also says to prepare a suggested plan on how the school might proceed including benefits and problems for parents students and teachers. OK. So what if we put these two together so you have checklists with space for writing here. (Observation of group using multimedia program)

After these initial steps, however, each group approached the task using different search strategies.

Each group agreed upon a different method of searching through the assessment strategies and the media elements within each strategy. It was thought that the list of strategies on the whiteboard in the main interface might prompt students to simply follow the order of strategies and to then move systematically through the media elements, through all the filing cabinet drawers and all the videos. While this was the approach adopted by Group 4, the other groups chose to use the whiteboard listing more flexibly. For example, Group 1 chose to read all the documents in the Descriptions drawer of the filing cabinet before accessing any other elements.

Such a finding endorses the referential navigation system incorporated within the interactive multimedia program, and enables each group using the resource to create individual search strategies best suited to the needs of their own unique response to the investigation.

\section{Summary and conclusions}

The analysis of the transcripts and careful viewing of the videotapes suggests that the students used the interactive multimedia program based on situated learning very differently to the way they might use some other types of computer-based resources, such as computer games and the Internet. 
Although the students' experience of interactive multimedia use prior to the use of the assessment program was limited, and computer experience was not a pre-requisite for use, they were able to freely navigate the resource to access the media elements. The students experienced a sense of magic and amazement at what they were able to do with the program and many expressed an almost childlike sense of fun. However, as well as the positive aspects of the program, students also expressed feelings of annoyance in dealing with technical problems, which clearly caused frustration and distracted them from the task. Nevertheless, none of the technical problems was severe enough to impede their productive use of the resource.

Students responded very positively to the ecological or intuitive interface design and to the sound effects, which generally provided feedback on the selection of an element. They generally found the interface was logical in its layout and very easy to use, and several expressed the view that you always knew where to find things. The students appreciated the non-linear layout of the program and the freedom to access material in the order of their own choosing. Several students noted that the notebook could be accessed from any point in the program and that this complemented the non-linear nature of the package. The ease of access of the notebook also facilitated students' ability to reflect on their learning.

Knowing where to look without the fear of getting lost was identified as a vital consideration in using computer-based resources. The referential navigation system ensured that any node of information was accessible within two clicks of the mouse, and generally students found it to be comparatively simple and effortless. They were able to return quickly to the main interface without having to follow links through several layers of materials with the possibility of not finding their way back.

Search strategies employed by students varied considerably between groups, although all the groups approached the task systematically rather than randomly, opting either to investigate the resource by strategy or by media element. Three initial orienting steps were common to all groups. They sought out the scope and depth of the resource by freely sampling elements, they re-established the task before them and then decided upon an initial search strategy. Each group then used a different search path to examine the materials and purposefully seek information.

Students used the program reflectively. They spent a good amount of time attending to the content of the program, but unlike traditional university instruction, proportionally more time was spent reflecting and discussing 
issues with their partners, and composing their response. They enjoyed using the program and valued the choice and self-control it allowed in their learning about assessment.

It is interesting to note that there was a relatively consistent response among the students in relation to the program itself and this response was a mix of amazement, appreciation and enthusiasm for the power of this electronic medium as a support for learning. But at the same time there were many differences observed in the ways in which the students used the multimedia package and these diferences all had the prospect to influence the learning outcomes achieved.

These findings suggest that the use of the situated learning model can be a successful design strategy for interactive multimedia programs. They also serve to remind us that in instances where learners are empowered and are enabled to assume higher degrees of responsibility for their activity and conduct in a learning setting, we need to be cognisant of the various design factors which can impede or enhance learning. In multimedia environments, these include such elements as the motivational aspects of the environment, the interface design, and the navigation elements employed. As well as research which explores learning outcomes achieved through various design models, it is also important to practice research which explores the impact of the more tangible aspects of multimedia design such as those explored in this study.

\section{References}

Brown, J.S., Collins, A., \& Duguid, P. (1989). Situated cognition and the culture of learning. Educational Researcher, 18(1), 32-42.

Clarke, A.C. (1973). Profiles of the future: An inquiry into the limits of the possible (2nd ed.). London: Pan.

Collins, A. (1988). Cognitive apprenticeship and instructional technology (Technical Report No. 6899). BBN Labs Inc., Cambridge, MA.

Collins, A., Brown, J.S., \& Newman, S.E. (1989). Cognitive apprenticeship: Teaching the crafts of reading, writing, and mathematics. In L.B. Resnick (Ed.), Knowing, learning and instruction: Essays in honour of Robert Glaser (pp. 453-494). Hillsdale, NJ: LEA.

Cuban, L. (1996, 27 October). Computers in the classroom: Revolutions that fizzled. The Washington Post, p. R01.

Eisner, E.W. (1991). The enlightened eye: Qualitative inquiry and the enhancement of educational practice. New York: Macmillan. 
Harnden, R.J., \& Stringer, R. (1993). Theseus: The evolution of a hypermedium. Cybernetics and systems, 24(3), 255-262.

Hedberg, J., \& Harper, B. (1996). Interactive educational technologies: Effective design and application in the classroom. In C. McBeath \& R. Atkinson (Eds.), The learning superhighway: New world? New worries? (pp. 160-168). Perth, WA: Promaco Conventions. http://www .ascilite.org.au/asetarchives/confs/iims/1996/ek/hedberg2.html

Herrington, A.J., Sparrow, R.L., Herrington, J., \& Oliver, R.G. (1997). Investigating assessment strategies in mathematics classrooms [Book and CD-ROM]. Perth: MASTEC, Edith Cowan University.

Herrington, J., \& Oliver, R. (1995). Critical characteristics of situated learning: Implications for the instructional design of multimedia. In J. Pearce \& A. Ellis (Eds.), Learning with technology (pp. 235-262). Parkville, Vic: University of Melbourne.

Jonassen, D.H., \& Reeves, T.C. (1996). Learning with technology: Using computers as cognitive tools. In D.H. Jonassen (Ed.), Handbook of research on educational communications and technology (pp. 693-719). New York: Macmillan.

McCracken, G. (1988). The long interview. Newbury Park, CA: Sage.

Miles, M.B., \& Huberman, A.M. (1994). Qualitative data analysis: An expanded sourcebook (2nd. ed.). Thousand Oaks, CA: Sage.

Morrison, M. (1994). The magic of interactive entertainment. Indianapolis, IN: Prentice Hall.

Negroponte, N. (1995). Being digital. New York: Vintage.

Norman, D. (1993). Things that make us smart: Defending human attributes in the age of the machine. Reading, MA: Addison-Wesley.

Oliver, R., \& Herrington, J. (1995). Developing effective hypermedia instructional materials. Australian Journal of Educational Technology, 11(2), 8-22. http://www .ascilite.org.au/ajet/ajet11/oliver.html

Pejtersen, A. (1993, November). Ecological interface design for multimedia products. Paper presented at InTech Seminar. Perth, WA.

Postman, N. (1992). Technopoly: The surrender of culture to technology. New York: Alfred A. Knopf, Inc.

Qualitative Solutions \& Research (1993). NUD•IST [Computer software]. Melbourne: Author.

Schwier, R.A., \& Misanchuk, E.R. (1993). Interactive multimedia instruction. Englewood Cliffs, NJ: Educational Technology Publications. 
Sculley, J. (1988). Foreword. In S. Ambron \& K. Hooper (Eds.), Interactive multimedia: Visions of multimedia for developers, educators, and information providers (pp. vii-ix). Redmond, WA: Microsoft Press.

Slattery, L. (1995, May 20-21). Nightmare on techno street. The Weekend Australian Review, p. 1-2.

Spillane, R. (1997). Preface: Apple Report No. 2. [On-line research report]. Available: http://www .apple.com.au/documents/ApppleReport2.pdf.

Spiro, R.J., Vispoel, W.P., Schmitz, J.G., Samarapungavan, A., \& Boeger, A.E. (1987). Knowledge acquisition for application: Cognitive flexibility and transfer in complex content domains. In B.K. Britton \& S.M. Glynn (Eds.), Executive control processes in reading (pp. 177-199). Hillsdale, NJ: Lawrence Erlbaum Associates.

Stoll, C. (1995). Silicon snake oil: Second thoughts on the information highway. New York: Anchor.

Stringer, R. (1992). Theseus: A project at Liverpool Polytechnic to develop a hypermedia library for open and flexible learning. International Federation of Library Associations Journal, 18(3), 267-272.

Young, M.F., \& McNeese, M. (1993). A situated cognition approach to problem solving with implications for computer-based learning and assessment. In G. Salvendy \& M.J. Smith (Eds.), Human-computer interaction: Software and hardware interfaces New York: Elsevier Science Publishers. 